Brit. J. industr. Med., 1965, 22, 13.

\title{
A STUDY OF THE CONCENTRATIONS OF POLYCYCLIC AROMATIC HYDROCARBONS IN GAS WORKS RETORT HOUSES
}

\author{
BY \\ P. J. LAWTHER, B. T. COMMINS, and R. E. WALLER \\ From the Medical Research Council Air Pollution Research Unit, \\ St. Bartholomew's Hospital Medical College, London, E.C.1
}

(RECEIVED FOR PUBLICATION SEPTEMBER 30, 1964)

\begin{abstract}
Measurements of the concentration of 3:4-benzpyrene and other polycyclic aromatic hydrocarbons have been made in gas works retort houses of several types. The tarry fumes which escaped from retorts contained extremely high concentrations of polycyclic hydrocarbons, but in general men were only exposed to these very briefly. The mean concentration of $3: 4$-benzpyrene determined from long-period samples at sites representative of normal working conditions in three works was $3 \mu \mathrm{g} . / \mathrm{m}^{3}$, over 100 times the normal level in the City of London. Above the retorts in an old horizontal retort house the concentration was over $200 \mu \mathrm{g} . / \mathrm{m}^{3}$, about 10,000 times that in the City, and the 'top-man' working there could be exposed to this in the normal course of his duty. We found no working areas in the vertical retort houses where men could be exposed to such massive concentrations of polycyclic hydrocarbons. Apart from defining these special conditions above horizontal retorts our results did not reveal any gross differences in pollution of the general air in horizontal and continuous vertical retort houses.
\end{abstract}

The tarry material produced when coal is distilled during the manufacture of coal gas contains a large proportion of polycyclic aromatic hydrocarbons some of which are carcinogenic. Although precautions are taken to avoid the discharge of tarry fume into the working environment, some does escape, and an investigation was carried out to find whether men were exposed during their hours of employment to concentrations of polycyclic aromatic hydrocarbons greatly in excess of those measured in the general atmosphere.

The carcinogenic properties of coal tar have been studied for many years, and indeed much of our present-day knowledge of chemical carcinogens is based on the classical work carried out more than 30 years ago at the Royal Cancer Hospital using an extract of tar prepared by the Gas Light and Coke Company. The way in which this led to the identification of the polycyclic aromatic hydrocarbon 3:4-benzpyrene as one of the most potent carcinogenic components of the tar has been recalled by Kennaway (1955).

Although the connexion between exposure to tar and the development of skin cancer had been estab- lished beyond doubt, it was more difficult to determine whether there was any risk of carcinogenesis associated with the inhalation of tarry fumes in gas works. In an accompanying paper Doll, Fisher, Gammon, Gunn, Hughes, Tyrer, and Wilson (1965) have now shown from an eight-year study of the mortality of gasworkers that there is an increased mortality from lung cancer among men employed in retort houses. The work reported here was done to determine whether these men were exposed to concentrations of polycyclic aromatic hydrocarbons greatly in excess of those found in the general atmosphere. There was a suggestion from the mortality study that the risk was greater among men who had worked with horizontal retorts than among those who had worked with continuous vertical retorts. When we started our investigation in 1959, horizontal retorts were in use mainly at small works, and these were gradually being closed down so that production could be concentrated at large works having continuous vertical retorts or coke ovens. We first studied conditions in a horizontal retort house at Rochester, Kent before the opportunity was lost to us. We then went to a modern vertical retort 


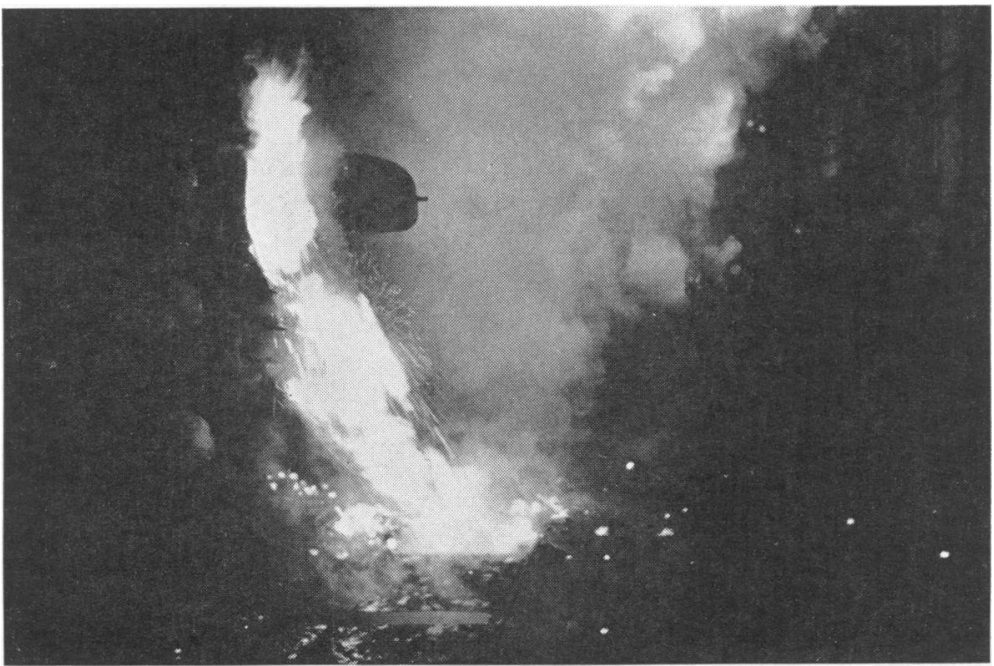

FIG. 1.-Quenching hot coke in the horizontal retort house at Rochester.
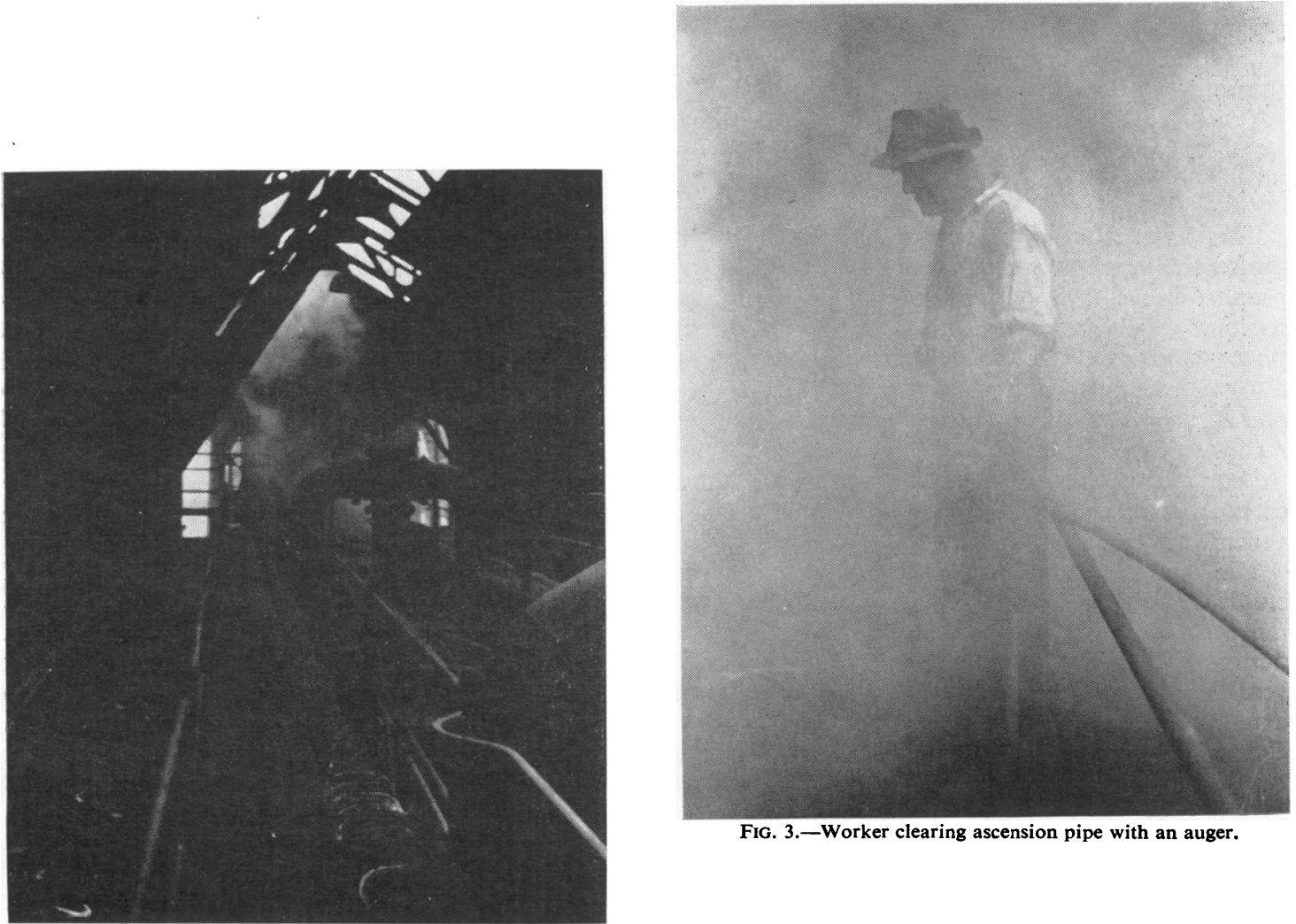

FIG. 3.-Worker clearing ascension pipe with an auger.

Fig. 2.-Above the retorts at Rochester. 
house near Brighton and to an old, but re-equipped one at Birmingham. The investigation was later extended to works in a few other areas.

\section{Description of Works Studied}

The Rochester works was situated in an open industrial area on the outskirts of the town close to the River Medway. The retort house contained 90 horizontal retorts with a total gas-making capacity of $2 \frac{1}{2}$ million cu. ft./day. Gas production ceased at the Rochester works in 1960, and the retort house has since been pulled down. At the level where most of the men worked the ventilation was good with strong draughts blowing through open doorways and unglazed windows. Visibility was greatly reduced when the hot coke from the retort was quenched in a stream of water, giving rise to clouds of steam (Fig. 1). These conditions prevailed for five to 10 minutes in every two hours, and the men were briefly enveloped in the steam. At other times not much pollution was visible in the working area around the retorts. Any tarry fumes which escaped into the air rose vertically, and the men employed in charging and discharging the retorts were not heavily exposed to the fumes. Above the retorts (Fig. 2) conditions were far worse: in addition to the fumes rising up from the face of the retorts there were also substantial amounts of tarry material emitted intermittently from 'ascension' pipes which carry the distillation products from the retorts to the gas main. Only one man worked directly above the retorts, the 'top-man', and he was particularly exposed to tarry fumes when he was unblocking open ascension pipes with an auger (Fig. 3). The man who operated the coal conveyor belt (above and to one side of the retorts) was also exposed to the tarry fumes to a limited extent.

The Portslade works, which we next visited, was on the sea-shore just to the west of the large residential area of Brighton and Hove. The retort house was a modern one which came into operation in 1953. It contained continuous vertical retorts with a total gas-making capacity of 15 million cu. $\mathrm{ft}$./day. The building was totally enclosed, and there were large windows at the levels where men worked. These were normally left open to maintain a comfortable temperature in the building, but in stormy weather they sometimes had to be closed. The general working conditions were much cleaner than those in the old horizontal retort house at Rochester, and the amount of physical work required of the men was less. There was also much less opportunity for the escape of steam, dust or tarry fumes into the retort house. The only operation involving regular exposure to tarry fumes was the 'rodding' which was

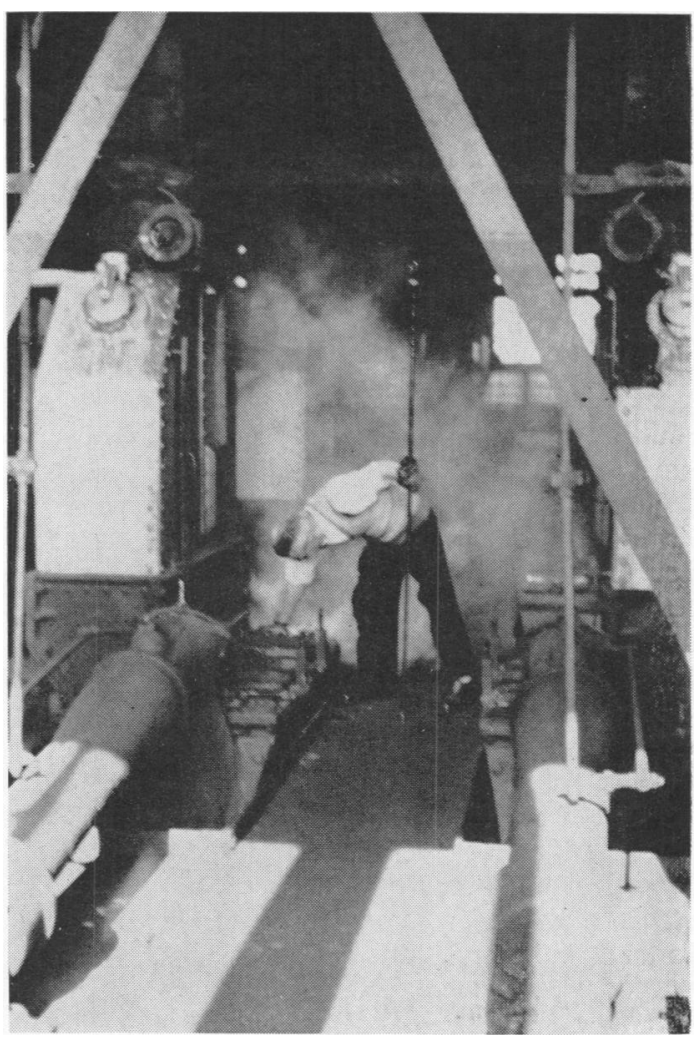

Fig. 4.-Worker rodding retorts at Portslade.

done at two-hourly intervals. This involved poking the coal with a long metal rod (Fig. 4) to maintain a steady flow through the retort, and sometimes tarry fumes escaped during the process. The retorts operated continuously for 28 days, but at the end of the cycle they were disconnected from the gas main, and at this stage of the process it was possible for relatively large amounts of tarry fumes to escape into the retort house over a period of a few hours. Some fumes were also emitted during the subsequent 'scurfing' operation when deposits were being burnt off the retorts. These operations increased the general level of pollution in the retort house, but they did not involve individual workers in severe exposure to tarry fumes. There was no working area comparable with that above the retorts at Rochester. The coal conveyor belts were situated above the retorts, but they were effectively separated from any rising fumes.

In Birmingham, most of our samples were taken at the Windsor St. works situated about a mile from the centre of the city in an area of factories and old terraced houses. The retort house was an old building, but it contained modern vertical retorts with a 
total gas-making capacity of 30 million cu. $\mathrm{ft}$./day. The building was well ventilated by means of openings in the walls and roof, and extractor fans had also been installed. Although the retorts were of the same design as those at Portslade, there were some minor differences in the mode of operation. The men there charged the retorts at hourly intervals and rodded them only when required; interruptions in the flow of coal were indicated remotely on a panel. There was again no working area comparable with that above the retorts at Rochester, and there did not appear to be anywhere in the works where men would be exposed to massive quantities of tarry fumes.

We also visited the nearby Saltley works in Birmingham, where some of the men had been accustomed to wearing masks in the course of their duties in the retort house. This gave us the opportunity to explore the use of masks as a sampling technique, but we did not install fixed samplers there. The works was smaller than the one at Windsor St., but it had the same type of continuous vertical retorts.

Later in our investigation we also arranged for mask sampling to be done at the Stapleton Rd. works, Bristol, where there were continuous vertical retorts, and at New Wortley, Leeds, one of the few works using intermittent vertical retorts.

\section{Sampling and Analytical Methods}

We wished to estimate the long-term exposure to tarry fumes of men in retort houses, and for this purpose we installed a continuous sampler at Rochester, Brighton (Portslade), and Birmingham (Windsor St.) successively. The sampler was in each case placed close to where men worked, with its air intake about $1 \mathrm{ft}$. above breathing level. The tar and other suspended matter were collected on weighed glass fibre filters contained in a 4-in. (10.16 $\mathrm{cm}$.) diameter brass filter holder. Air was drawn through the filter at a rate of 1.5 to 3 litres/min., and the total volume was recorded with a dry gas meter. At Brighton and Birmingham the filter holder, pump, and gas meter were contained in a metal cabinet. At Rochester it was not possible to place all the apparatus close to the sampling point, and to avoid using a long inlet tube we left the filter holder outside the cabinet and protected it from radiant heat with a bright metal shield. In all cases the temperature of the filter holder was maintained below $50^{\circ} \mathrm{C}$. It was shown in laboratory experiments (Commins and Lawther, 1958; Commins, 1961) that samples of hydrocarbons of special interest, notably $3: 4$-benzpyrene, once collected on a filter paper did not suffer appreciable loss at this temperature. Samples were collected for periods of two to four weeks, and at least two successive samples were taken at each works. We also took a number of samples over short periods (a few minutes to two hours) in dense fumes issuing from retorts. These were collected on weighed glass fibre filter sheets measur- ing 8 in. $\times 10$ in. $(20.32 \times 25.4 \mathrm{~cm}$. $)$ overall, using a Staplex high-volume sampler running at about $1.5 \mathrm{~m} .3 / \mathrm{min}$.

At Rochester we tried to assess the very high concentrations of pollution above the retorts using a mask technique. One of us wore an efficient industrial mask* for a period of one hour close to where one man was working. We could only estimate the volume of air inspired during that period, but another sample was taken simultaneously with a measured air flow using the portable sampler shown in Figure 5. In this the tar was collected on a filter made of the same material as that in the mask, backed with a glass fibre filter. This enabled us to determine the

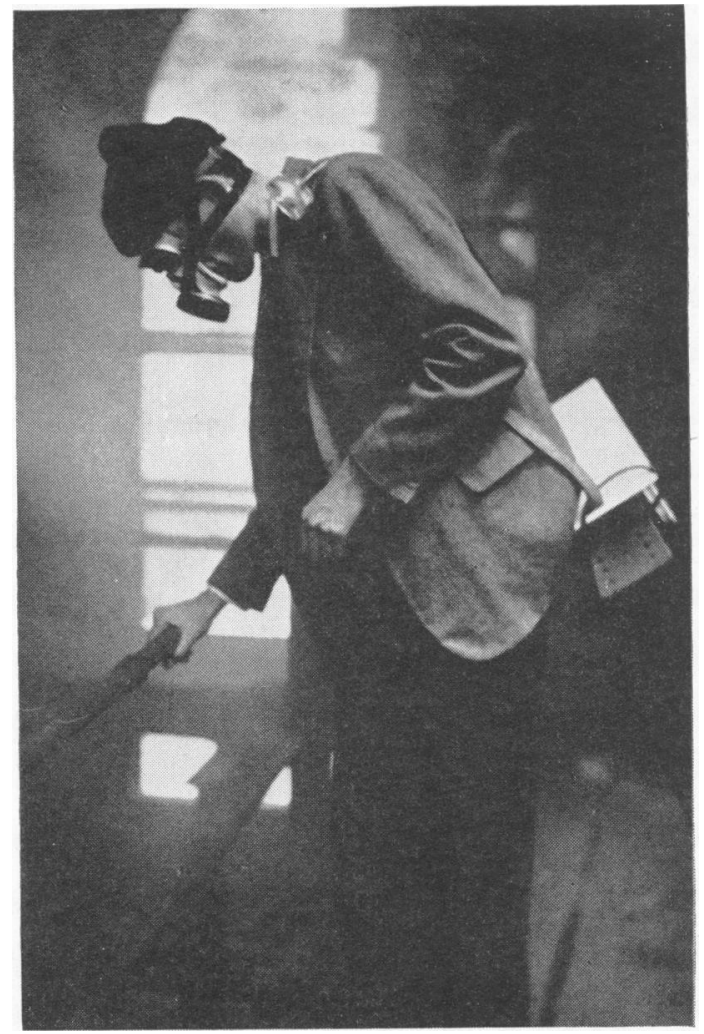

FIG. 5.-Mask and portable sampler in use at Rochester.

efficiency of the filter of the mask, and as the results showed it to be close to $100 \%$, we used the same type of mask in our further studies in other works. At Birmingham (Saltley), Bristol, and Leeds these masks were worn by retort house workers for one, and in some cases two, shifts, and the filters were returned to us for analysis.

The filters were extracted with cyclohexane for three hours in a Soxhlet apparatus, and the dark-coloured extract was reduced to small volume and transferred to a column of alumina. The hydrocarbons were separated chromatographically by elution with cyclohexane and

*Siebe Gorman Microfilter. 
determined spectrophotometrically (Commins, 1958a). The following hydrocarbons were detected in the samples: acenaphthylene, fluorene, phenanthrene, anthracene, fluoranthene, pyrene, chrysene, $\ddagger$ 1:2-benzanthracene, $\ddagger$ 1:2-benzpyrene, $\ddagger \quad$ 3:4-benzpyrene, $\dagger \quad$ 3:4-benzfluoranthene, $\ddagger$ 10:11-benzfluoranthene, $\ddagger$ 11:12-benzfluoranthene, $\ddagger 1: 12$-benzperylene, $\ddagger$ perylene, anthanthrene, and coronene. Some of these hydrocarbons are appreciably volatile at the ambient temperatures in gas works, and during collection unknown amounts could have been lost from the filters; some hydrocarbons are not completely stable in air and some could not be accurately determined with the analytical methods used. Only the amounts of $1: 2$-benzpyrene, 3:4-benzpyrene, $1: 12$-benzperylene, and coronene are quoted here since these hydrocarbons can be reliably determined under the conditions of sampling and analysis used in this study.

\section{Results}

The mean concentrations obtained from the analysis of the long-period samples are given in Table 1. The results are of the same order of magnitude in each of the three retort houses and they are much higher than those found in urban atmospheres.

TABLE 1

MEAN CONCENTRATION OF SUSPENDED MATTER AND POLYCYCLIC AROMATIC HYDROCARBONS IN THE RETORT HOUSE AIR OF GAS WORKS (LONG-PERIOD SAMPLES)

\begin{tabular}{|c|c|c|c|}
\hline & \multicolumn{3}{|c|}{$\begin{array}{l}\text { Concentration } \\
\left(\mu \mathrm{g} . / \mathrm{m}^{3} \text { air }\right)\end{array}$} \\
\hline & Rochester & $\begin{array}{l}\text { Brighton } \\
\text { (Portslade) }\end{array}$ & $\begin{array}{l}\text { Birmingham } \\
\text { (Windsor St.) }\end{array}$ \\
\hline Suspended Matter* & 1,000 & 925 & 1,100 \\
\hline $\begin{array}{l}\text { 1:2-Benzpyrene } \\
\text { Coronene } \\
\text { 1:12-Benzperylene } \\
\text { 3:4-Benzpyrene }\end{array}$ & $\begin{array}{l}2.5 \\
0.5 \\
2.5 \\
4.8\end{array}$ & $\begin{array}{l}0.9 \\
0.7 \\
2.4 \\
1.4\end{array}$ & $\begin{array}{l}1 \cdot 4 \\
0 \cdot 4 \\
1 \cdot 6 \\
2 \cdot 7\end{array}$ \\
\hline
\end{tabular}

*Consisting of tar with some coal dust.

The samples also contained a far higher proportion of polycyclic hydrocarbons than urban air pollution: at Rochester nearly $0.5 \%$ of the suspended matter was 3:4-benzpyrene. The results from 20 shortperiod samples which we took, mainly at Portslade, cxtended over a very wide range, and in Table 2 we have quoted only the maximum concentration of each pollutant. These then indicate the highest concentrations that could conceivably be breathed for very brief periods by a man in a retort house. Some of these samples contained over $1 \%$ of $3: 4$-benzpyrene.

The mask samples should give a direct measure of exposure to the polycyclic hydrocarbons for com-

†Indicates potent carcinogen.

†Indicates marginal carcinogenic activity.
TABLE 2

MAXIMUM CONCENTRATION OF SUSPENDED MATTER AND POLYCYCLIC AROMATIC HYDROCARBONS IN FUMES ESCAPING FROM RETORTS (SHORT-PERIOD SAMPLES)

\begin{tabular}{l|c}
\hline & $\begin{array}{c}\text { Concentration } \\
\left(\mu \mathrm{g} . / \mathrm{m} .^{3} \text { air } \dagger\right)\end{array}$ \\
\hline Suspended Matter* & 374,100 \\
\hline 1:2-Benzpyrene & 1,010 \\
Coronene & 2,460 \\
$1: 12-$ Benzperylene & 2,250 \\
3:4-Benzpyrene & 2,330 \\
\hline
\end{tabular}

*Consisting of tar only.

†The figures refer to the maximum for each pollutant in 20 samples of varying composition.

TABLE 3

MEAN SHIFT EXPOSURE TO POLYCYCLIC AROMATIC HYDROCARBONS IN RETORT HOUSES (MASK SAMPLES)

\begin{tabular}{|c|c|c|c|c|}
\hline & \multicolumn{4}{|c|}{ Exposure per Eight-hr. Shift ( $\mu \mathrm{g})}$. \\
\hline & Rochester & $\begin{array}{c}\text { Birming- } \\
\text { ham } \\
\text { (Saltley) }\end{array}$ & Bristol & Leeds \\
\hline $\begin{array}{l}\text { No. of Masks } \\
\text { Analysed }\end{array}$ & 1 & 4 & 3 & 6 \\
\hline $\begin{array}{l}1: 2 \text {-Benzpyrene } \\
\text { Coronene } \\
1: 12 \text {-Benzperylene } \\
\text { 3:4-Benzpyrene }\end{array}$ & $\begin{array}{r}495 \\
83 \\
557 \\
1,136\end{array}$ & $\begin{aligned} & 27(23-35) \\
& 8(4-18) \\
& 33(29-36) \\
& 56(42-84)\end{aligned}$ & $\begin{array}{|cc|}16 & (5-25) \\
4 & (0-7) \\
21 & (4-36) \\
37 & (13-61) \\
\end{array}$ & $\begin{array}{l}1(0-6) \\
0(0) \\
1(0-5) \\
3(0-12)\end{array}$ \\
\hline
\end{tabular}

The figures in parentheses refer to the range.

plete shifts, and the results are expressed in this form in Table 3. Since there was some variation in the time for which each mask was worn, the results have all been calculated as for an eight-hour shift. One of the masks used at Bristol and several of those used at Leeds gave very low results, hardly higher than would be expected from urban air pollution; it is possible that these results may be due to bad fit but they have been included when calculating the mean values. To enable us to compare the results with those from the long-period samples we have also estimated mean concentrations in the air from the mask samples by assuming that a man breathes $10 \mathrm{~m}^{3}$ of air during an eight-hour shift (I.C.R.P., 1959). The result from the mask worn by one of us for one hour at Rochester has been multiplied by eight for inclusion in Table 3. The portable sampler which we used at the same time gave a concentration of 3:4-benzpyrene of $216 \mu \mathrm{g} . / \mathrm{m}^{3}$; comparison with the result from the mask sample would indicate that the breathing rate was $5.25 \mathrm{~m} .3$ /eight-hour shift, about half of that assumed for the working man.

Particle Size Distribution.-At Rochester samples were taken in the retort house with a cascade impactor and a thermal precipitator for microscopic examination of the particles and droplets present in the air. The samples consisted mainly of very small 
tarry droplets: their size could not be estimated satisfactorily with the optical microscope, and further samples were taken at Rochester and Portslade for examination with the electronmicroscope. The droplets were then seen to vary between 0.1 and 1 micron in diameter (Waller, Brooks, and Cartwright, 1963) and all could therefore be considered to be respirable. We did not find 'smoke aggregates' of the type seen in domestic pollution, but some coaldust particles were present with diameters from about one micron upwards.

\section{Discussion}

In Table 4 the concentrations of the carcinogenic hydrocarbon 3:4-benzpyrene found in this study have been compared with those which we have measured elsewhere. The long-period and mask samples give similar results and show that men working in retort houses are exposed to concentrations of 3:4-benzpyrene that are more than 100 times those normally found in the City of London. The

TABLE 4

CONCENTRATION OF 3:4-BENZPYRENE IN RETORT HOUSES AND OTHER ENVIRONMENTS

\begin{tabular}{|c|c|}
\hline & $\begin{array}{l}\text { Concentration } \\
\left(\mu \mathrm{g} . / \mathrm{m} .^{3} \text { air }\right)\end{array}$ \\
\hline $\begin{array}{l}\text { Maximum in fumes escaping from retorts } \\
\text { Above horizontal retorts (Rochester, portable } \\
\text { sampler) } \\
\text { Mean of all mask results (Saltley, Bristol, Leeds) } \\
\text { Mean of all long-period results (Rochester, } \\
\text { Portslade, Windsor St.) } \\
\text { Highest found in urban air (short period) } \ddagger \\
\text { Blackwall Tunnel, rush hours } \\
\text { Industrial town (Salford), mean annual } \dagger \\
\text { Among traffic, Fleet St., mean annual } \\
\text { City of London, away from traffic, mean annual } \$ \\
\text { Small country town (Wetherby), mean annual } \dagger \\
\text { Rural area (Conway Valley), winter* }\end{array}$ & $\begin{array}{l}2,330 \\
216 \\
3 \\
3 \\
2 \\
0 \cdot 2 \\
0 \cdot 1 \\
0 \cdot 04 \\
0 \cdot 02 \\
0 \cdot 01 \\
0.001\end{array}$ \\
\hline $\begin{array}{l}\text { *Commins (1958b). } \\
\text { †Stocks, Commins, and Aubrey (1961). } \\
\text { ¡Waller, Commins, and Lawther (1961). } \\
\text { §Waller, Commins, and Lawther (1965). }\end{array}$ & \\
\hline
\end{tabular}

very high urban figure of $2 \mu \mathrm{g} . / \mathrm{m}^{3}$ quoted was found during a temperature inversion and lasted for a few hours only. Apart from this instance we have not found any sustained concentration of 3:4-benzpyrene, even in the more polluted industrial towns, or in busy streets or poorly ventilated tunnels which approached those found in retort houses. The sample taken above the retorts at Rochester represents more than 10,000 times the average level of 3:4-benzpyrene in the City of London, and one man was exposed to this in the normal course of his duty. This is probably the most important point to note when any comparison is sought between the conditions in horizontal and vertical retort houses.
Although we had found even higher concentrations in the plumes issuing straight from retorts in both horizontal and vertical retort houses, men could only be exposed to these very briefly. Apart from defining the specially high concentrations above the horizontal retorts at Rochester the techniques we used did not reveal any gross differences in pollution in the general atmosphere of the retort houses studied. The results from the long-period samples (Table 1) showed that the mean concentrations of polycyclic hydrocarbons in the horizontal retort house (Rochester) were greater than those in the two vertical retort houses (Portslade and Birmingham), but since there were variations in the results from successive samples taken in each works we could not establish without a more extensive study whether there was a consistent difference between the pollution in the two types of retort house.

Our pilot experiments using masks were carried out to try to assess exposures directly without having to consider variations in concentration from one part of the retort house to another. There are obvious difficulties in the use of masks as samplers; it is sometimes difficult to ensure that they fit perfectly, and a leak will lead to an underestimate of pollution; conversely, the usual exposure may be overestimated because the man, protected by a mask, may venture into a highly polluted atmosphere which he would normally avoid. The 'personal' samplers which have been developed in recent years (Sherwood and Greenhalgh, 1960) would not be subject to the same disadvantages, but we considered that we had already obtained sufficient information for our present purpose by the use of masks and fixed samplers.

We can summarize our present findings as follows:

(a) Retort house workers are liable to be exposed to much higher concentrations of polycyclic aromatic hydrocarbons than is the general population.

(b) A wide range of exposures is to be expected in any retort house but there is one working environment, above horizontal retorts, where exposures may be far greater than elsewhere.

(c) Apart from the special conditions above horizontal retorts, for which there is no counterpart in a vertical retort house, we have not in our present study demonstrated any gross differences between the pollution in the two types of retort house.

It follows that the total amount of 3:4-benzpyrene and other polycyclic hydrocarbons inhaled by a gasworker during his working life will be strongly influenced by whether he has been employed as a topman in a horizontal retort house for any substantial period. Many works have changed from horizontal to continuous vertical retorts during the past few decades and it is therefore difficult to assess the 
overall exposure of long-service employees. One further point that was brought to our notice was the fact that all of the works had to be 'blacked-out' during the Second World War. This was said to restrict the ventilation, and the whole atmosphere of the retort house was then far more polluted than at present. Some of the men included in the study of Doll et al. (1965) could have been employed in retort houses during this period.

Our findings are of interest in relation to general atmospheric pollution, but it is important to distinguish between the type of pollution which we have found in the retort houses and that in urban air. In a retort coal is distilled in the absence of air, and the products include tar, carbon monoxide, and other combustible gases together with some hydrogen sulphide, but with very little sulphur dioxide or black smoke. When coal is burnt on a domestic fire, distillation products, including tar, are emitted each time the fire is refuelled but there is combustion with emission of smoke and sulphur dioxide. In more efficient heating appliances little tar or smoke is produced, and the main products are $\mathrm{CO}_{2}$ and sulphur dioxide. Other sources, such as motor vehicles, emit different pollutants; the composition of the mixture present in urban air has been discussed by Commins (1962). Some tar, containing 3:4-benzpyrene and other polycyclic hydrocarbons, is present in the air throughout Great Britain, and the increased incidence of lung cancer among retort house workers exposed to tar is therefore relevant to the study of lung cancer in the general population. The results of this study and that of Doll et al. (1965) should be considered in relation to two alternative hypotheses. It has been shown (Stocks, 1960) that the urban/rural gradient in lung cancer mortality is associated with exposure to 3:4-benzpyrene in the air. From a consideration of the lung cancer mortality among retort house workers and in the general population it is apparent that the relationship between mortality and exposure to 3:4-benzpyrene is far from linear. If a non-linear relationship between dose and death were assumed then the increased mortality among gasworkers could be compatible with Stocks' hypothesis. On the other hand, there may be other explanations of Stocks' findings (Buck and Brown, 1964; Waller, 1965). The failure to find a more massive discrepancy between gasworkers and the general public despite the gross differences in exposure might well be interpreted as an indication that 3:4-benzpyrene is of doubtful relevance in these populations. These questions may be answered if the continued study should reveal any great excess of mortality among the top-men compared with retort house workers.

Any link between the increased mortality from chronic bronchitis among retort house workers (Doll et al., 1965) and the occurrence of this disease in the general population is more difficult to establish. It has not previously been suggested that tarry fumes are concerned in the development of this disease, but this is the only common urban pollutant present in retort houses in substantially higher concentrations than are found outside. Many studies have indicted air pollution as a possible factor in the development of chronic bronchitis. Pemberton and Goldberg (1954) showed a relationship between mortality from chronic bronchitis and pollution by sulphur dioxide, although this gas should perhaps be regarded in Britain as but an index of general pollution. In one of the retort houses (Portslade) the possibility of exposure to sulphur dioxide was considered. The general atmosphere of the retort house was found to be alkaline rather than acid: the concentration of ammonia was more than sufficient to neutralize the sulphur dioxide when both were absorbed in dilute hydrogen peroxide. It is not known whether these gases effectively neutralize one another when inhaled together, but the concentration of sulphur dioxide (0.35 p.p.m.) was within the normal range found in urban air. One operation led to the release of sulphur dioxide into the retort house atmosphere: when a hot retort was filled with coke after having been scurfed, fumes containing sulphur dioxide were emitted for about 15 minutes. This happened three times a day, but the men tended to avoid this local pollution by gas and dust. By sampling in the worst of the fumes we found a concentration of 6 p.p.m. of sulphur dioxide. This is more than is found in the general atmosphere but it is only just outside the maximum allowable concentration for eight-hour exposures in industry (5 p.p.m.). Since the men could only have been exposed to these conditions momentarily and since we could find no other source of sulphur dioxide in the retort house we concluded that there could be no special hazard from this pollutant in gas works. Other occupational studies have suggested that exposure to dust may be a factor in the development of chronic bronchitis (Higgins, Cochrane, Gilson, and Wood, 1959) and although we did not examine this aspect in detail, it was obvious that the men were exposed to more dust than the general population. In the horizontal retort house at Rochester much coal and coke dust was dispersed into the air but most of it was too coarse to inhale.

In conclusion we should stress that the present study was undertaken in an attempt to assess the probable exposure to polycyclic aromatic hydrocarbons of men who had worked in retort houses at any time prior to 1961 . If the mortality study continues, the effect of progressive changes in gas pro- 
duction will have to be noted. As an increasing proportion of gas supplies in Great Britain is being derived from oil, from imported methane, and from the complete gasification of coal, any hazards associated with the distillation of coal in what is now regarded as obsolescent equipment should eventually disappear.

This study has been carried out in close co-operation with the South Eastern, West Midlands, South Western, and North Eastern Gas Boards, and we have received invaluable assistance from the Medical Officers of the Boards and from the staff at each of the works visited.
REFERENCES

Buck, S. F., and Brown, D. A. (1964). Tobacco Research Council, Research Paper No. 7.

Commins, B. T. (1958a). Analyst, 83, 386.

(1958b). Int. J. Air Pollut., 1, 14.

(1961). National Cancer Institute, Monograph No. 9, 225.

(1962). Research, 15, 421 .

and Lawther, P. J. (1958). Brit. J. Cancer, 12, 351.

Doll, R., Fisher, R. E. W., Gammon, E. J., Gunn, W., Hughes, G. O., Tyrer, F. H., and Wilson, W. (1965). Brit. J. industr. Med., 22, 1 .

Higgins, I. T. T., Cochrane, A. L., Gilson, J. C., and Wood, C. H. (1959). Ibid., 16, 255.

I.C.R.P. (1959). International Committee on Radiological Protection. Report of Committee No. 2. Pergamon Press.

Kennaway, E. L. (1955). Brit. med. J., 2, 749.

Pemberton, J., and Goldberg, C. (1954). Ibid., 2, 567.

Sherwood, R. J., and Greenhalgh, D. M. S. (1960). Ann. occup. Hyg., $2,127$.

Stocks, P. (1960). Brit. J. Cancer, 14, 397.

Commins, B. T., and Aubrey, K. V. (1961). Int. J. Air Wat.

Waller, R. E.'(1965). In preparation.

Brooks, A. G. F., and Cartwright, J. (1963). Int. J. Air Wat. Pollut., 7, 779,

Commins, B. T., and Lawther, P. J. (1961). Brit. J. industr. Med., $18,250$.

$\longrightarrow,-, \quad(1965)$. In preparation. 